\title{
Molecular identification and characterization of Sarcocystis spp. in horsemeat and beef marketed in Japan
}

\author{
Rie Murata, Jun Suzuki*, Ayako Hyuga, Takayuki Shinkai, and Kenji Sadamasu \\ Department of Microbiology, Tokyo Metropolitan Institute of Public Health, 3-24-1 Hyakunincho, Shinjuku-ku, \\ Tokyo 169-0073, Japan
}

Received 20 December 2017, Accepted 16 April 2018, Published online 8 May 2018

\begin{abstract}
Human Sarcocystis infections are known to be caused by the ingestion of raw or undercooked beef or pork containing mature sarcocysts of Sarcocystis hominis or S. suihominis, respectively. In addition, several cases of parasitic food poisoning in Japan have recently been reported after consumption of raw horsemeat containing sarcocysts of $S$. fayeri. In this study, the presence of sarcocysts in 28 horsemeat and 121 beef samples collected in Tokyo was investigated. Sarcocysts of $S$. fayeri were found in 16 horsemeat samples. Sarcocysts of S. hominis were not detected in beef samples, while sarcocysts of $S$. cruzi were detected in 60 beef samples. In addition, S. hirsuta and S. bovini were isolated only from New Zealand beef samples. Bradyzoites in sarcocysts collected from $62 / 73$ sarcocyst-positive refrigerated horsemeat and beef samples were determined to be viable. Molecular analysis of $S$. fayeri $18 \mathrm{~S}$ rRNA gene sequences revealed that intraspecific variation among eight individual bradyzoites from a single sarcocyst was as high as $9.8 \%$. In contrast, mitochondrial cytochrome c oxidase subunit 1 (mtDNA cox1) gene sequences from the six fragments of a single sarcocyst were $100 \%$ identical. Sarcocysts of $S$. bovini isolated from beef also exhibited intraspecific variation in $18 \mathrm{~S} \mathrm{rRNA}$ gene sequences and had to be cloned before sequencing, while mtDNA cox1 gene sequences were obtained by direct sequencing. Therefore, we conclude that molecular analysis of the mtDNA cox1 gene is the most useful for identification of Sarcocystis species. This study provides the first published partial sequence of the $S$. fayeri mtDNA cox1 gene.
\end{abstract}

Keywords: Sarcocystis fayeri, Sarcocystis cruzi, 18S rRNA, mtDNA cox1, intraspecific variation

Résumé - Identification moléculaire et caractérisation de Sarcocystis spp. dans les viandes de cheval et bœuf commercialisées au Japon. Les infections humaines par Sarcocystis sont causées par l'ingestion de viande de bœuf ou de porc, crue ou insuffisamment cuite, contenant des sarcocystes mûrs de Sarcocystis hominis ou de S. suihominis, respectivement. En outre, plusieurs cas d'intoxication alimentaire parasitaire ont récemment été signalés au Japon après consommation de viande de cheval crue contenant des sarcocystes de $S$. fayeri. Dans cette étude, la présence de sarcocystes dans 28 échantillons de cheval et 121 échantillons de bœuf collectés à Tokyo a été étudiée. Des sarcocystes de $S$. fayeri ont été trouvés dans 16 échantillons de viande de cheval. Des sarcocystes de $S$. hominis n'ont pas été détectés dans les échantillons de bœuf, alors que des sarcocystes de $S$. cruzi ont été détectés dans 60 échantillons de bœuf. De plus, $S$. hirsuta et $S$. bovini n'ont été isolés qu'à partir d'échantillons de bœuf néo-zélandais. Les bradyzoïtes des sarcocystes prélevés sur $62 / 73$ échantillons de viande de cheval et de viande de bœuf réfrigérés positifs aux sarcocystes ont été jugés viables. L'analyse moléculaire des séquences du gène de l'ARNr de $S$. fayeri a révélé que la variation intraspécifique entre huit bradyzoïtes individuels d'un seul sarcocyste atteignait 9,8\%. En revanche, les séquences du gène de la sous-unité 1 de la cytochrome c oxydase mitochondriale (ADNmt cox1) provenant des six fragments d'un seul sarcocyste étaient identiques à $100 \%$. Les sarcocystes de S. bovini isolés du bœuf présentaient également une variation intraspécifique des séquences du gène de l'ARNr 18S et ont dû être clonés avant le séquençage, tandis que les séquences du gène cox1 ont été obtenues par séquençage direct. Par conséquent, nous concluons que l'analyse moléculaire du gène cox1 est la plus utile pour l'identification des espèces de Sarcocystis. Cette étude fournit la première séquence partielle publiée du gène cox1 de S. fayeri.

\footnotetext{
*Corresponding author: jun_suzuki@member.metro.tokyo.jp
} 


\section{Introduction}

The genus Sarcocystis includes intracellular protozoan parasites that parasitize many different animals, including mammals, birds, and fish. They have an obligatory prey-predator (intermediate-definitive) twohost life cycle; they reproduce asexually in herbivores and omnivores as intermediate hosts, and sexually in carnivores as definitive hosts [2,4]. Identification of Sarcocystis spp. is based on morphological characteristics of the sarcocyst and host information, such as the host species and the prepatent period [2]. However, morphological diagnosis of sarcocysts is difficult as some Sarcocystis spp. share sarcocyst morphologies and intermediate hosts; for example, S. hominis, S. bovifelis, and $S$. bovini are all found in cattle. Additionally, morphological changes occur with sarcocyst aging and in relation to the locations of intermediate hosts $[2,4]$. Recently, molecular methods, particularly sequencing of $18 \mathrm{~S}$ ribosomal RNA (rRNA), have been increasingly used to complement morphological data in the identification of Sarcocystis species [6].

Sarcocystosis in humans presents as two forms. The first is intestinal sarcocystosis caused by Sarcocystis hominis and Sarcocystis suihominis, which use humans as definitive hosts. The other is muscular sarcocystosis caused when humans become dead-end hosts for nonhuman Sarcocystis spp. after the accidental ingestion of oocysts. Recently, food poisoning manifesting as transient vomiting and diarrhea has been reported after consumption of raw horsemeat in Japan [8]. Sarcocystis fayeri sarcocysts in horsemeat were found to induce diarrhea following oral inoculation of bradyzoites in rabbits [15]. In this study, we investigated the presence of $S$. fayeri sarcocysts in horsemeat (Equus caballus) and of $S$. hominis sarcocysts in beef (Bos taurus). Additionally, sarcocysts were identified and characterized by molecular methods.

\section{Materials and methods Meat samples}

A total of 28 horsemeat samples were obtained from wholesale merchants, retail meat shops, and mail-order vendors in Japan from June to December 2012. Among these, 13 were refrigerated Japanese samples, 13 were imported from Canada (six refrigerated samples and seven frozen samples), and two were refrigerated samples imported from Italy (Table 1). A total of 121 refrigerated beef samples were obtained from retail meat shops and mail-order vendors in Japan from May 2013 to December 2015. These consisted of 75 Japanese samples (28 hearts, ten tongues, 12 diaphragms, and 25 rounds), 21 imported samples from the United States of America (USA) (ten tongues, nine diaphragms, and two rounds), 20 imported samples from Australia (four tongues, four diaphragms, ten rounds, and two rib roasts), and five imported samples from New Zealand (five rounds) (Table 2).
Table 1. Detection of Sarcocystis fayeri from horsemeat.

\begin{tabular}{llcll}
\hline $\begin{array}{l}\text { Country } \\
\text { of origin }\end{array}$ & $\begin{array}{l}\text { refrigerated } \\
\text { frozen }\end{array}$ & Tested & $\begin{array}{l}\text { No. of } \\
\text { positive } \\
\text { samples }\end{array}$ & $\begin{array}{l}\text { No. of viable } \\
\text { bradyzoite } \\
\text { samples }\end{array}$ \\
\hline Japan & refrigerated & 13 & 4 & 3 \\
Canada & refrigerated & 6 & 6 & 5 \\
& frozen & 7 & 5 & 0 \\
Italy & refrigerated & 2 & 1 & 1 \\
\hline
\end{tabular}

\section{Isolation and microscopic examination of sarcocysts}

From each horsemeat and beef sample, 5 slices (app. $5 \times 3 \times 1 \mathrm{~cm}$ ) were examined under a stereoscopic microscope. Sarcocysts were isolated with small tweezers and transferred to a drop of phosphate-buffered saline (PBS) on a glass slide. Sarcocysts were determined to be thin- or thick-walled under a light microscope without a coverslip.

The viability of bradyzoites in sarcocysts was assayed using two methods. In the trypan blue dye exclusion assay, a bradyzoite suspension on a glass slide was added to an equal volume of $0.4 \%$ trypan blue solution (Thermo Fisher Scientific, USA), and immediately examined under a light microscope. In the second assay, the resistance of bradyzoites in sarcocysts to enzymatic digestion was determined. The sarcocyst was suspended in $1 \mathrm{~mL}$ of digestive fluid ( $1 \mathrm{~g}$ of pepsin, $0.8 \mathrm{~mL}$ of concentrated $\mathrm{HCl}$, and PBS to $50 \mathrm{~mL}$ ), incubated at $37^{\circ} \mathrm{C}$ for $30 \mathrm{~min}$, and centrifuged at $9,000 \mathrm{~g}$ for 1 min before the supernatant was discarded. The pellet was immediately observed under a light microscope to determine whether bradyzoites were digested.

\section{DNA extraction}

For DNA extraction from bradyzoites isolated from horsemeat, one sarcocyst was divided into six parts with a disposable scalpel. Three of the six cyst fragments were individually placed into $0.8 \% \mathrm{NaCl}$ in a Petri dish, and each cyst fragment was broken apart using small tweezers in order to release the bradyzoites. Bradyzoites in suspension were counted with a Neubauer improved cell counting chamber and adjusted to a final concentration of $1-3$ bradyzoites in $5 \mu \mathrm{L}$ of $0.8 \% \mathrm{NaCl}$. The adjusted bradyzoite suspension $(5 \mu \mathrm{L})$ was placed in a $0.2 \mathrm{~mL}$ tube. Next, $25 \mu \mathrm{L}$ of a DNA extraction mixture containing $3 \mu \mathrm{L}$ of $10 \times$ Ex Taq Buffer (Takara Bio, Japan), $5 \mu \mathrm{L}$ of $10 \%$ Triton X-100, and $17 \mu \mathrm{L}$ of $\mathrm{H}_{2} \mathrm{O}$ was added and incubated at $95^{\circ} \mathrm{C}$ for $30 \mathrm{~min}$ with a heating block.

DNA was extracted from individual sarcocysts and from each of the six individual cyst fragments (including the three from which bradyzoite DNA had been extracted) using the QIAamp DNA Mini Kit (Qiagen, Netherlands).

\section{PCR amplification}

For the first PCR amplification of $18 \mathrm{~S}$ rRNA from S. fayeri bradyzoites (app. 1900 bp), DNA templates were 
Table 2. Detection of Sarcocystis spp. from refrigerated beef.

\begin{tabular}{|c|c|c|c|c|c|c|c|c|c|}
\hline \multirow{3}{*}{$\begin{array}{l}\text { Country of origin } \\
\text { Japan }\end{array}$} & \multirow{3}{*}{$\begin{array}{l}\text { Muscle part } \\
\text { heart }\end{array}$} & \multirow{3}{*}{$\begin{array}{l}\text { Tested } \\
28\end{array}$} & \multicolumn{6}{|c|}{ No. of positive samples (\%) } & \multirow{3}{*}{$\begin{array}{l}\begin{array}{l}\text { No. of viable } \\
\text { bradyzoite samples }\end{array} \\
22\end{array}$} \\
\hline & & & \multicolumn{2}{|c|}{ S. cruzi } & \multicolumn{2}{|c|}{ S. hirsuta } & \multicolumn{2}{|c|}{ S. bovini } & \\
\hline & & & 22 & $(78.6)$ & 0 & & 0 & & \\
\hline & tongue & 10 & 6 & $(60.0)$ & 0 & & 0 & & 2 \\
\hline & diaphragm & 12 & 4 & $(33.3)$ & 0 & & 0 & & 4 \\
\hline & round & 25 & 2 & $(8.0)$ & 0 & & 0 & & 1 \\
\hline & total & 75 & 34 & $(45.3)$ & 0 & & 0 & & 29 \\
\hline \multirow[t]{4}{*}{ United States of America } & tongue & 10 & 9 & $(90.0)$ & 0 & & 0 & & 8 \\
\hline & diaphragm & 9 & 7 & $(77.8)$ & 0 & & 0 & & 7 \\
\hline & round & 2 & 0 & & 0 & & 0 & & 0 \\
\hline & total & 21 & 16 & $(76.2)$ & 0 & & 0 & & 15 \\
\hline \multirow[t]{5}{*}{ Australia } & tongue & 4 & 3 & $(75.0)$ & 0 & & 0 & & 3 \\
\hline & diaphragm & 4 & 2 & $(50.0)$ & 0 & & 0 & & 1 \\
\hline & round & 10 & 3 & $(30.0)$ & 0 & & 0 & & 1 \\
\hline & rib roast & 2 & 1 & $(50.0)$ & 0 & & 0 & & 1 \\
\hline & total & 20 & 9 & $(45.0)$ & 0 & & 0 & & 6 \\
\hline New Zealand & round & 5 & $1^{\mathrm{a}}$ & $(20.0)$ & 1 & $(20.0)$ & 3 & $(60.0)$ & 3 \\
\hline
\end{tabular}

a $S$. cruzi, S. hirsuta, and $S$. bovini were detected in this sample.

each added to a $20 \mu \mathrm{L}$ reaction mixture containing $2 \mu \mathrm{L}$ of $10 \times$ Ex Taq Buffer, $4 \mu \mathrm{L}$ of $2.5 \mathrm{mM}$ each dNTP, $2 \mu \mathrm{L}$ of $10 \mu \mathrm{M}$ each primer (ER1B1 and PrimerB; Table 3), $0.2 \mu \mathrm{L}$ of $5 \mathrm{U} / \mu \mathrm{L}$ Ex Taq (Takara Bio, Japan), and $9.8 \mu \mathrm{L} \mathrm{H}_{2} \mathrm{O}$. The second PCR was performed in a $50 \mu \mathrm{L}$ reaction mixture containing $1 \mu \mathrm{L}$ of the first PCR product, $1 \mathrm{U}$ of Ex Taq, $0.4 \mu \mathrm{M}$ of each primer, and $0.2 \mathrm{mM}$ of each dNTP. Primer pairs included ER1B1/Sar18S619R (app. 600 bp), 18S1F/18S11R (app. $950 \mathrm{bp),} \mathrm{Sar-UF/18S11R} \mathrm{(app.}$ 950 bp), Sar-UF/ShR2 (app. 850 bp), Sar18S674F/Primer 1H (app. $650 \mathrm{bp}$ ), and Sar18S1149F/PrimerB (app. $700 \mathrm{bp}$ ) (Table 3). The following cycling parameters were used: initial denaturation at $94^{\circ} \mathrm{C}$ for $5 \mathrm{~min}$; 35 cycles of $94{ }^{\circ} \mathrm{C}$ for $30 \mathrm{~s}, 60^{\circ} \mathrm{C}$ for $30 \mathrm{~s}$, and $72^{\circ} \mathrm{C}$ for $1 \mathrm{~min}$; and a final extension at $72^{\circ} \mathrm{C}$ for $5 \mathrm{~min}$.

PCR of sarcocysts and cyst fragments was used to amplify the $18 \mathrm{~S}$ rRNA gene and the mitochondrial cytochrome c oxidase subunit 1 (mtDNA cox1) gene. Amplification was performed with the same method as that used for the second PCR of bradyzoites. The $18 \mathrm{~S}$ rRNA gene was amplified using the primer pair ER1B1/ PrimerB (Table 3 ). The cycling parameters were the same as those for bradyzoites. The amplified Sarcocystis $18 \mathrm{~S}$ rRNA gene was cloned using the Qiagen PCR Cloning Kit (Qiagen, Netherlands). The mtDNA cox1 gene was amplified using the forward primer SF1 and reverse primers SR5 (for S. fayeri), COIRm (for Sarcocystis cruzi and Sarcocystis bovini), and CoxS1R (for Sarcocystis hirsuta) as previously described (Table 3) [6]. The following cycling parameters were used: initial denaturation at $95^{\circ} \mathrm{C}$ for $15 \mathrm{~min} ; 45$ cycles of $94^{\circ} \mathrm{C}$ for $30 \mathrm{~s}, 52^{\circ} \mathrm{C}$ for $30 \mathrm{~s}$, and $72^{\circ} \mathrm{C}$ for $90 \mathrm{~s}$; and a final extension at $72^{\circ} \mathrm{C}$ for $10 \mathrm{~min}$.

\section{Sequence and phylogenetic analysis}

PCR products of the $18 \mathrm{~S}$ rRNA and mtDNA cox1 genes were sequenced using the ABI Prism BigDye Terminator v3.1 Cycle Sequencing Ready Reaction Kit and ABI Prism 3500 Genetic Analyzer (Thermo Fisher Scientific, USA). Primers used for sequence analysis included Primer 3L, NSF1179/18, 18SR11-1, SarfCOX1F, Sarf-COX1R, Sarc-COX1R, Sarh-COX1R, and Sarb-COX1R, in addition to PCR primers (Table 3 ).

For analysis of $18 \mathrm{~S}$ rRNA sequences, bases corresponding to positions $153-1283$ of the $S$. cruzi $18 \mathrm{~S}$ rRNA gene (KT901167) were used. For analysis of mtDNA cox1, sequences longer than 812 bp were truncated at their $3^{\prime}$ end. Multiple alignment of the $18 \mathrm{~S}$ rRNA sequences of the Sarcocystis species was conducted as previously reported with ClustalW, using a gap opening penalty of 10 and a gap extension penalty of 0.2 for both pairwise and multiple alignment [7,17]. The phylogenetic analyses of the $18 \mathrm{~S}$ rRNA and mtDNA cox1 genes were performed using the maximum likelihood (ML) and maximum parsimony (MP) methods within MEGA version 6 [16]. As the ML analytical model gave the highest log likelihood, the ML tree was derived using a general time-reversible model employing estimates of the proportion of invariable sites and a Gamma distribution with five rate categories; statistical support was evaluated using bootstrapping with 1,000 replicates. The phylogeny based on MP analysis was tested with 1,000 replicates and the Tree-Bisection-Regrafting algorithm.

GenBank accession numbers of the Sarcocystis species used in the phylogenetic analysis are shown in Figure 1. Eimeria tenella sequences (GenBank accession numbers U67121 and HQ702484 for the 18S rRNA and mtDNA 
Table 3. Oligonucleotide primers used for PCR.

\begin{tabular}{|c|c|c|c|c|}
\hline DNA region & Primer name & Orientation & Primer sequence (5' to 3 ') & Reference \\
\hline \multirow[t]{13}{*}{ 18S rRNA } & ERlB1 & Forward & ACCTGGTTGATCCTGCCAG & {$[10]$} \\
\hline & PrimerB & Reverse & GATCCTTCTGCAGGTTCACCTAC & [10] \\
\hline & $18 \mathrm{~S} 1 \mathrm{~F}$ & Forward & GGATAACCGTGGTAATTCTATG & [13] \\
\hline & $18 \mathrm{~S} 11 \mathrm{R}$ & Reverse & TCCTATGTCTGGACCTGGTGAG & [13] \\
\hline & Primer 3L & Forward & CTAGTGATTGGAATGATGGG & [18] \\
\hline & Primer $1 \mathrm{H}$ & Reverse & TATCCCCATCACGATGCATAC & [18] \\
\hline & NSF1179/18 & Forward & AATTTGACTCAACACGGG & [9] \\
\hline & Sar-UF & Forward & GCTTTCGACGGTAGTGTATTGGA & This study \\
\hline & Sar18S674F & Forward & GCGAAAGCATTTGCCAARGATG & This study \\
\hline & Sar18S1149F & Forward & AGTATGGTCGCAAGGCTG & This study \\
\hline & Sar18S619R & Reverse & ACGCTATTGGAGCTGGAATTAC & This study \\
\hline & $\mathrm{ShR} 2$ & Reverse & AGTTTCAGCCTTGCGACCATA & This study \\
\hline & 18SR11-1 & Reverse & TCCCATGTCTGGACCTGGTGAG & This study ${ }^{a}$ \\
\hline \multirow[t]{9}{*}{ mtDNA $\operatorname{cox} 1$} & SF1 & Forward & ATGGCGTACAACAATCATAAAGAA & {$[6]$} \\
\hline & SR5 & Reverse & TAGGTATCATGTAACGCAATATCCAT & {$[6]$} \\
\hline & COIRm & Reverse & CCCAGAGATAATACAAAATGGAA & [6] \\
\hline & CoxS1R & Reverse & TTACCCATGACCACACCTGTAGTACC & [6] \\
\hline & Sarf-COX1F & Forward & TTCTCTACGTCTGGTCGATAGT & This study \\
\hline & Sarf-COX1R & Reverse & AATACTATCGACCAGACGTAGAGA & This study \\
\hline & Sarc-COX1R & Reverse & AGTATGAGCATTAAAGCCGTGAA & This study \\
\hline & Sarh-COX1R & Reverse & AACATACAGCACTCCAGATT & This study \\
\hline & Sarb-COX1R & Reverse & AGACGTACAGAATACCACATC & This study \\
\hline
\end{tabular}

a Modification of primer $18 \mathrm{~S} 11 \mathrm{R}$ described in reference [13].

cox1 genes, respectively) were used as outgroups to root the final phylogenetic tree.

\section{Results \\ Microscopic detection of Sarcocystis in horsemeat and beef}

Sarcocysts isolated from horsemeat exhibited thick and radially striated cyst walls, consistent with $S$. fayeri sarcocysts $[2,3]$. These sarcocysts were found in 16 samples, including four Japanese, 11 Canadian, and one Italian sample. Of these, bradyzoites in sarcocysts collected from three refrigerated Japanese, five refrigerated Canadian, and one refrigerated Italian sample were determined to be viable, while bradyzoites collected from one refrigerated Japanese, one refrigerated Canadian, and five frozen Canadian horsemeat samples were dead (Table 1).

Sarcocysts isolated from beef could be morphologically classified into three types $[2,5,12]$. The first type exhibited thin cyst walls with hair-like protrusions, consistent with $S$. cruzi sarcocysts (Figure 2A). These sarcocysts were found in 34 Japanese (22 hearts, six tongues, four diaphragms, and two rounds), 16 US samples (nine tongues and seven diaphragms), nine Australian samples (three tongues, two diaphragms, three rounds, and one rib roast), and one New Zealand sample (round). The second type of cysts was macroscopically visible with thick and radially striated cyst walls, consistent with $S$. hirsuta sarcocysts (Figure 2B). These sarcocysts were found in a single New Zealand beef sample that contained all three types of sarcocysts. The third type exhibited thick and radially striated cyst walls, similar to $S$. hominis sarcocysts (including Sarcocystis bovifelis and S. bovini) (Figure 2C). This type was found in three New Zealand beef samples. Non-viable bradyzoites in sarcocysts were found in five Japanese samples (four tongues and one round), one US sample (tongue), and three Australian samples (one diaphragm and two rounds), while the bradyzoites collected from the remaining beef samples were determined to be viable (Table 2).

\section{Molecular identification of sarcocysts}

Of the 16 sarcocyst-positive horsemeat samples, we were unable to conduct molecular analysis on the sarcocysts from two Japanese samples. Five sarcocysts (Sf10-C20 to Sf14-C20) were isolated from a single Canadian horsemeat sample (C20), and one of these was divided into six parts (Sf10-1-C20 to Sf10-6-C20) before DNA was extracted from each of the six individual cyst fragments. From the other 13 horsemeat samples, individual, intact sarcocysts were used for molecular analysis. Of the 23 cyst or cyst-fragment DNA samples, a clear, single-peak chromatogram of a $1861 \mathrm{bp}$ sequence of the $18 \mathrm{~S}$ rRNA gene was obtained from only a single sarcocyst (Sf5-ITA7), isolated from an Italian horsemeat sample. PCR amplification of the other sarcocyst DNA samples isolated from Canadian and Japanese horsemeat yielded ambiguous sequences, including multiple peaks at 

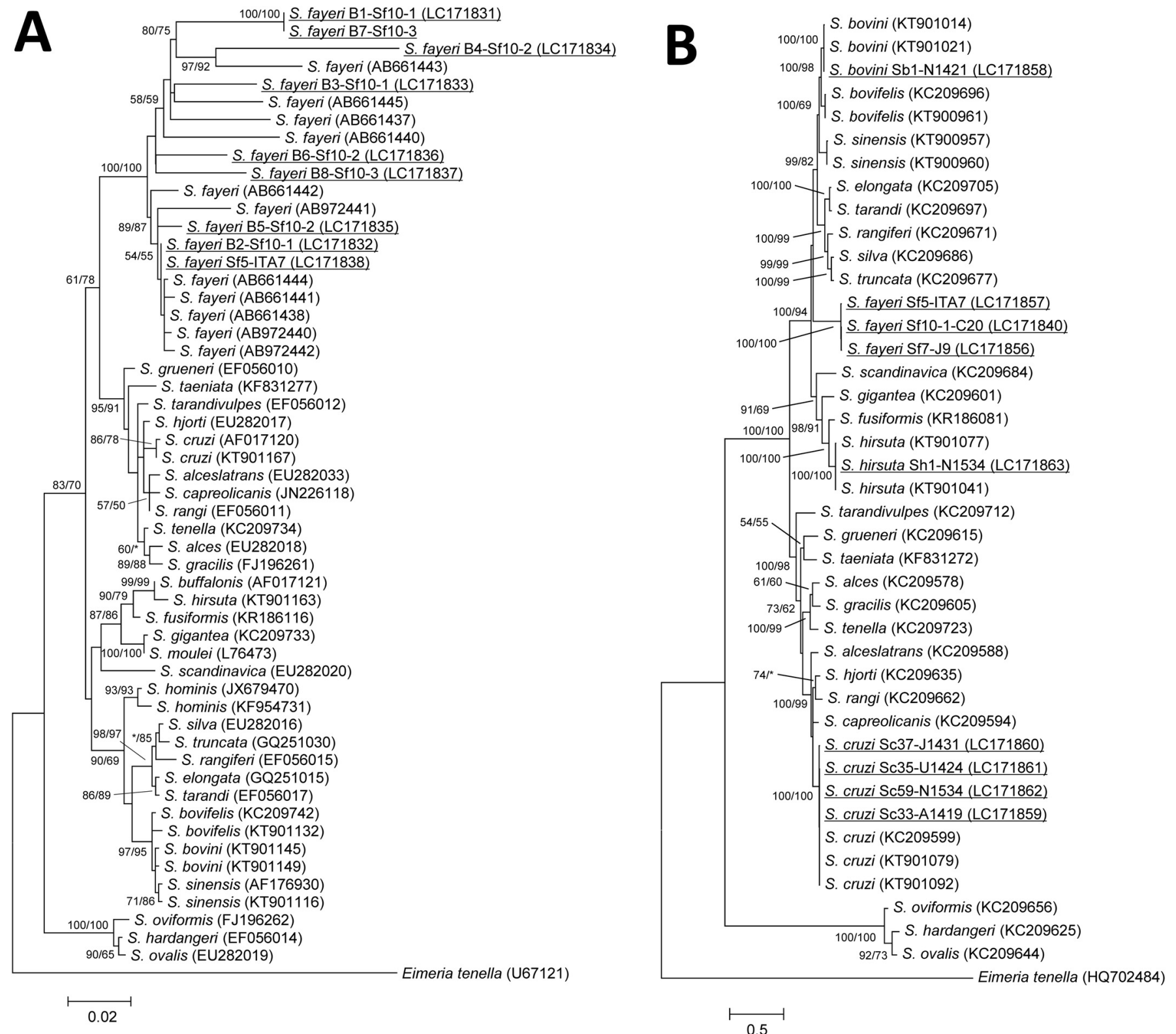

Figure 1. Phylogenetic relationships obtained by maximum likelihood (ML) analysis of Sarcocystis $18 \mathrm{~S}$ rRNA (A) and mtDNA cox1 (B) gene sequences.

ML trees were derived using a general time-reversible model employing estimates of the proportion of invariable sites and the Gamma distribution. Significant bootstrap support (> 50\%) from 1,000 replicates of the ML and the maximum parsimony (MP) method are shown above each node in the order ML/MP. Support for a node of less than $50 \%$ is indicated by an asterisk. Underlined samples are those sequenced in this study. The scale bar represents the distance in substitutions per nucleotide. GenBank accession numbers are shown in parentheses.

several positions in the chromatograms. Amplicons from each of these sarcocysts were cloned, and five clones derived from one sarcocyst isolated from Canada and 12 clones from one sarcocyst isolated from Japan were sequenced. In the $18 \mathrm{~S}$ rRNA phylogenetic analyses, these sequences clustered with the $S$. fayeri group, and genetic distances among clones from Canada and Japan, generated with the Kimura 2-parameter model, were 0.003-0.069 and $0.006-0.108$, respectively.

Eight sequences with clear, individual chromatogram peaks were obtained by sequencing of individual bradyzoites
(B1-Sf10-1-B3-Sf10-1, B4-Sf10-2-B6-Sf10-2, B7-Sf10-3, and B8-Sf10-3) released from a single sarcocyst (Sf10) using nested PCR of the 18S rRNA gene. Of these, two sequences (B1-Sf10-1 and B7-Sf10-3) were 100\% identical. The other six sequences exhibited high intraspecific variation when compared with each other. Among the pairwise genetic distances between the eight sequences, the highest genetic distance between a pair of sequences was 0.094, and the average genetic distance was 0.059 . In the phylogenetic tree of $18 \mathrm{~S}$ rRNA gene sequences, these eight sequences formed several clusters with reference strains of $S$. fayeri (Figure 1 ). 

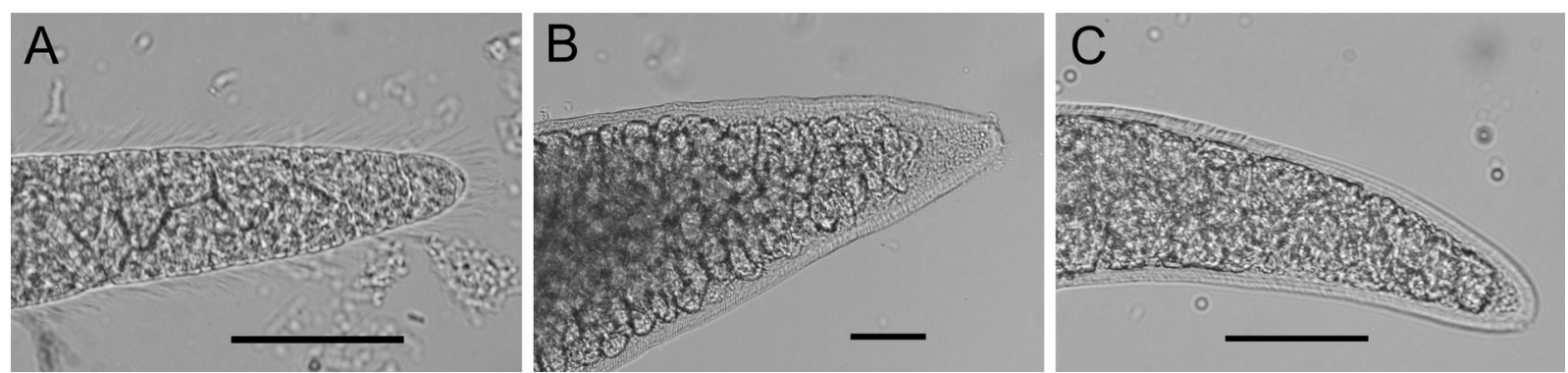

Figure 2. Morphology of Sarcocystis spp. isolated from beef. A, Sarcocystis cruzi; B, Sarcocystis hirsuta; C, Sarcocystis bovini. Bar: $50 \mu \mathrm{m}$.

Table 4. Summary of polymorphic sites in the mtDNA cox1 gene (812 bp) of Sarcocystis fayeri sarcocysts isolated from horsemeat.

\begin{tabular}{|c|c|c|c|c|c|c|c|c|c|c|c|c|c|c|c|c|c|c|c|c|c|c|c|c|c|c|c|c|c|c|c|c|c|c|c|c|c|c|c|}
\hline \multirow[t]{2}{*}{ Origin } & \multirow{2}{*}{$\begin{array}{l}\text { Isolate } \\
\text { name }\end{array}$} & \multirow{2}{*}{$\begin{array}{l}\text { GenBank } \\
\text { accession } \\
\text { number }\end{array}$} & \multicolumn{37}{|c|}{ Position $^{\mathrm{a}}$} \\
\hline & & & $\hat{\sim}$ & aे & 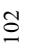 & $\stackrel{ }{\Xi}$ & さे & $\stackrel{\vec{m}}{\stackrel{m}{ }}$ & 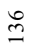 & $\stackrel{\infty}{\stackrel{\infty}{0}}$ & $\stackrel{\infty}{\infty}$ & $\stackrel{\Omega}{2}$ & $\stackrel{\sim}{\sim}$ & $\underline{\vec{\sim}}$ & $\stackrel{n}{\stackrel{2}{c}}$ & $\stackrel{\sim}{\sim}$ & $\stackrel{\infty}{\stackrel{\sim}{े}}$ & so & $\stackrel{\circ}{\text { m }}$ & すे & iे & ले & $\stackrel{\circ}{\circ}$ & in & $\underset{⿱}{\stackrel{+}{+}}$ & $\begin{array}{l}\infty \\
\infty \\
+\end{array}$ & gे & $\stackrel{\circ}{n}$ & 3 & $\begin{array}{l}\text { cै } \\
\text { r. }\end{array}$ & î & 古 & $\stackrel{\infty}{\sigma}$ & గิ & 交 & $\stackrel{n}{n}$ & $\underset{⿱}{\mathbb{N}}$ & $\stackrel{\infty}{\sim}$ & $\vec{\infty}$ \\
\hline \multirow[t]{20}{*}{$\overline{\text { Canada }}$} & Sf10-1-C20 & LC171840 & $\mathrm{A}$ & $\mathrm{C}$ & $\mathrm{A}$ & $\mathrm{T}$ & $\mathrm{T}$ & $\mathrm{Y}$ & $\mathrm{C}$ & $\mathrm{T}$ & $\mathrm{A}$ & $\mathrm{T}$ & $\mathrm{T}$ & $\mathrm{C}$ & $\mathrm{A}$ & $\mathrm{C}$ & $\mathrm{T}$ & $\mathrm{C}$ & $\mathrm{T}$ & $\mathrm{A}$ & $\mathrm{G}$ & $\mathrm{T}$ & G & $\mathrm{C}$ & $\mathrm{C}$ & G & $\mathrm{A}$ & A & $A$ & $\mathrm{~A}$ & $\mathrm{C}$ & G & $\mathrm{T}$ & G & G & $\mathrm{T}$ & $\mathrm{A}$ & $\mathrm{T}$ & $\mathrm{T}$ \\
\hline & Sf10-2-C20 & & - & - & - & - & - & . & - & - & - & - & - & - & - & - & - & - & • & - & - & - & - & - & - & - & • & & & . & - & - & - & - & - & - & - & & • \\
\hline & Sf10-3-C20 & & - & • & - & - & - & - & - & • & - & • & - & - & - & - & - & - & - & - & - & - & • & • & - & - & • & • & • & - & - & • & • & • & - & - & - & - & • \\
\hline & Sf10-4-C20 & & . & . & . & . & . & . & . & . & . & . & . & . & . & . & . & . & . & . & . & . & . & . & . & . & . & & • & . & . & . & . & . & . & . & . & . & . \\
\hline & Sf10-5-C20 & & . & . & . & . & . & . & . & . & . & . & . & . & . & . & . & . & . & . & . & . & . & . & . & . & . & & . & . & . & . & . & . & . & . & . & . & . \\
\hline & Sf10-6-C20 & & - & - & - & - & . & . & . & - & . & - & . & - & - & - & - & - & - & - & - & - & - & - & - & - & • & 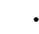 & . & . & . & - & - & - & - & . & . & - & • \\
\hline & Sf11-C20 & LC171841 & G & - & - & - & . & $\mathrm{T}$ & - & - & . & - & - & - & - & - & $\mathrm{C}$ & - & - & . & . & - & - & . & - & - & - & . & • & - & - & - & - & - & - & $\mathrm{C}$ & - & - & $\mathrm{C}$ \\
\hline & Sf12-C20 & LC171842 & G & - & - & • & $\mathrm{C}$ & $\mathrm{T}$ & - & - & - & • & - & - & - & - & $\mathrm{C}$ & Y & • & - & - & - & • & • & - & - & • & • & • & . & $\mathrm{T}$ & $\mathrm{A}$ & • & • & A & - & - & • & • \\
\hline & Sf13-C20 & LC171843 & G & • & • & • & • & $\mathrm{T}$ & • & - & - & - & • & $\mathrm{Y}$ & - & . & $\mathrm{C}$ & . & . & - & $\mathrm{R}$ & - & - & . & - & - & • & • & - $\mathrm{C}$ & G & . & - & - & - & - & . & - & - & • \\
\hline & Sf14-C20 & LC171844 & G & . & . & . & $\mathrm{C}$ & $\mathrm{T}$ & . & $\mathrm{C}$ & . & . & . & . & . & . & $\mathrm{C}$ & . & . & . & • & - & $\mathrm{A}$ & $\mathrm{T}$ & • & - & - & - & . & . & . & . & . & . & - & . & . & . & - \\
\hline & $\overline{\text { Sf1-C1 }}$ & LC171845 & $\mathrm{G}$ & $\cdot$ & $\cdot$ & $\cdot$ & $\mathrm{C}$ & $\mathrm{T}$ & $\cdot$ & $\cdot$ & $\cdot$ & $\cdot$ & $\mathrm{C}$ & $\cdot$ & $\cdot$ & $\cdot$ & $\mathrm{C}$ & $\cdot$ & $\cdot$ & $\cdot$ & $\cdot$ & $\mathrm{G}$ & $\cdot$ & $\cdot$ & $\cdot$ & $\cdot$ & $\cdot$ & $\cdot$ & $\cdot$ & $\cdot$ & $\cdot$ & $\mathrm{A}$ & $\cdot$ & $\cdot$ & $\cdot$ & $\cdot$ & $\cdot$ & $\mathrm{C}$ & $\mathrm{C}$ \\
\hline & Sf2-C2 & LC171846 & G & • & • & - & • & $\mathrm{T}$ & • & • & - & • & • & - & • & - & $\cdot$ & $\cdot$ & - & • & - & - & - & - & • & • & • & • & • & $\cdot$ & • & • & - & • & - & • & $\cdot$ & • & • \\
\hline & Sf3-C3 & LC171847 & $\mathrm{G}$ & - & - & • & $\mathrm{Y}$ & $\mathrm{T}$ & - & - & - & - & - & - & $\mathrm{C}$ & - & - & - & A & - & - & - & • & $\mathrm{T}$ & - & - & • & • & • & - & - & - & • & • & - & - & . & • & • \\
\hline & Sf6-C8 & LC171848 & G & - & $\cdot$ & - & $\mathrm{C}$ & $\mathrm{T}$ & - & • & - & • & - & - & • & - & $\mathrm{C}$ & - & • & - & - & G & • & - & - & - & G & & • & - & - & - & • & - & - & - & $\mathrm{G}$ & • & • \\
\hline & Sf8-C18 & LC171849 & G & $\cdot$ & • & • & $\mathrm{Y}$ & $\mathrm{T}$ & • & • & • & • & • & • & • & • & • & • & • & • & • & - & • & • & - & - & • & • & • & $\cdot$ & - & • & - & • & - & • & • & • & • \\
\hline & Sf9-C19 & LC171850 & G & • & • & - & • & $\mathrm{T}$ & • & • & - & • & • & - & - & - & $\mathrm{C}$ & • & • & M & - & - & - & • & - & - & • & • & • & • & • & • & $\mathrm{C}$ & • & - & • & $\cdot$ & • & • \\
\hline & Sf15-C21 & LC171851 & $\mathrm{G}$ & . & - & - & . & $\mathrm{T}$ & . & . & . & - & . & . & - & - & - & - & - & . & - & - & - & $\mathrm{T}$ & - & - & • & • & • & . & . & - & - & - & - & . & . & - & • \\
\hline & Sf16-C25 & LC171852 & G & - & - & - & $\mathrm{C}$ & $\mathrm{T}$ & - & • & . & - & - & . & . & - & $\mathrm{C}$ & - & - & . & - & - & - & - & - & $\mathrm{C}$ & • & G & & . & . & - & • & - & - & - & - & - & • \\
\hline & Sf17-C27 & LC171853 & G & $\cdot$ & • & • & • & $\mathrm{T}$ & - & - & • & Y & • & - & . & - & • & . & . & • & • & • & • & • & A & • & • & • & • & . & - & A & • & • & - & $\mathrm{C}$ & • & - & • \\
\hline & Sf18-C28 & LC171854 & $\mathrm{G}$ & • & • & • & • & $\mathrm{T}$ & - & • & G & - & - & - & - & Y & - & - & • & - & - & - & $\mathrm{A}$ & • & - & - & • & • & • & $\cdot$ & - & • & • & • & - & • & • & • & • \\
\hline \multirow[t]{2}{*}{ Japan } & Sf4-J5 & LC171855 & G & $\mathrm{T}$ & G & • & $\cdot$ & $\mathrm{T}$ & A & • & $\cdot$ & $\cdot$ & $\cdot$ & $\cdot$ & . & $\cdot$ & $\mathrm{C}$ & $\cdot$ & . & • & $\cdot$ & - & $\cdot$ & • & • & - & • & $\cdot$ & • & $\cdot$ & $\cdot$ & $\cdot$ & • & $\cdot$ & - & $\cdot$ & $\cdot$ & $\mathrm{C}$ & $\mathrm{C}$ \\
\hline & Sf7-J9 & LC171856 & G & . & . & $\mathrm{G}$ & $\mathrm{C}$ & $\mathrm{T}$ & . & . & . & . & . & • & . & . & . & . & . & . & • & - & . & • & - & - & - & - & • & . & . & . & . & . & . & $\cdot$ & $\cdot$ & • & - \\
\hline Italy & Sf5-ITA7 & LC171857 & $\mathrm{G}$ & . & . & . & . & $\mathrm{T}$ & . & . & . & . & . & . & . & . & $\mathrm{C}$ & . & . & . & . & . & . & . & . & . & . & • & . & . & . & . & . & A & . & $\mathrm{C}$ & . & & $\mathrm{C}$ \\
\hline
\end{tabular}

Dots indicate matches to the Sf10-1-C20 sequence.

a Nucleotide position from the 5' end of LC171840.

Sequence analysis was also performed on the mtDNA cox 1 gene from the 23 cysts or cyst fragments isolated from horsemeat samples. These 23 cyst samples were identified as $S$. fayeri based on similarity searches of the $18 \mathrm{~S}$ rRNA gene sequences using BLAST. The sequences from the six cyst fragments (Sf10-1-C20 to Sf10-6-C20) of a single sarcocyst (Sf10) from one Canadian horsemeat sample (C20) were $100 \%$ identical. In contrast, sequences from four sarcocysts (Sf11-C20 to Sf14-C20) isolated from the same sample (C20) and from 13 sarcocysts isolated from the other horsemeat samples contained 5-8 and 2-9 base substitutions, respectively, when compared with the sequence obtained from all six cyst fragments (Table 4). In the mtDNA cox 1 phylogenetic tree, the 23 cyst and cyst-fragment sequences formed a monophyletic cluster (Figure 1B; only three sarcocyst samples are shown). Eight partial sequences of the $18 \mathrm{~S}$ rRNA gene and 18 partial sequences of the mtDNA cox 1 gene of $S$. fayeri were deposited in GenBank with accession numbers LC171831LC171838 and LC171840-LC171857, respectively.

On the basis of the molecular analysis of $S$. fayeri sarcocysts, the mtDNA cox1 gene was more useful in the identification of sarcocysts than the $18 \mathrm{~S}$ rRNA gene. Therefore, sarcocysts isolated from beef were analyzed using sequences of the mtDNA cox1 gene. In the phylogenetic tree of the mtDNA cox1 gene, sarcocysts exhibiting the morphological characteristics of the S. cruzi, S. hirsuta, and S. hominis types clustered with S. cruzi, S. hirsuta, and S. bovini, respectively (Figure 1B; only four $S$. cruzi, one $S$. hirsuta, and one $S$. bovini isolates are shown). However, there were no mtDNA cox1 gene sequences for S. hominis found in GenBank. Therefore, S. hominis-type sarcocysts were further analyzed by sequencing the $18 \mathrm{~S}$ rRNA gene, resulting in ambiguous sequences, which were further delineated by cloning. Five clones of one $S$. hominis-type sarcocyst were sequenced, 
and the genetic distances among them were 0.005-0.016. In the $18 \mathrm{~S}$ rRNA phylogenetic analyses, these five sequences belonged to the same cluster of $S$. bovini, and this cluster was separate from the $S$. hominis sequences. Partial mtDNA cox1 gene sequences of four $S$. cruzi, one S. hirsuta, and one S. bovini isolate were deposited in GenBank with accession numbers LC171859-LC171862, LC171863, and LC171858, respectively. Partial 18S rRNA gene sequences of four $S$. cruzi and one $S$. hirsuta isolate were deposited in GenBank with accession numbers LC171827-LC171830 and LC171839, respectively.

\section{Discussion}

\section{Detection of Sarcocystis spp. in horsemeat and beef}

In this study, although it was difficult to obtain a large sample size, $S$. fayeri sarcocysts were found more often in Canadian horsemeat than in Japanese horsemeat, consistent with the results of previous research, in which the prevalence of $S$. fayeri sarcocyst infections in Japanese horses was $42.9 \%$ and that in horses that were born abroad and bred in Japan was $100 \%$ [14]. Bradyzoites in sarcocysts collected from $9 / 11$ refrigerated horsemeat samples infected with $S$. fayeri were viable. Thus, vomiting and diarrhea may be induced following the ingestion of raw refrigerated horsemeat.

Among beef samples, S. hominis sarcocysts were not detected, and $S$. cruzi was the most prevalent species. The prevalence of $S$. cruzi sarcocyst infections in cattle were reported to be significantly higher in hearts than those in other organs [11]. In this study, the prevalence of $S$. cruzi sarcocyst infections was higher in Japanese beef hearts than those in tongues, diaphragms, and rounds. Comparison of Japanese and imported beef samples revealed that the prevalence of $S$. cruzi sarcocyst infections was particularly high in US tongues and diaphragms and in Australian tongues. Bradyzoites in sarcocysts collected from most refrigerated beef samples infected with $S$. cruzi were determined to be viable. In addition to $S$. cruzi, S. hirsuta and S. bovini were isolated from New Zealand beef samples, and these bradyzoites were viable. Sarcocysts of $S$. bovini, S. hominis, and S. bovifelis in cattle have thick and radially striated cyst walls. The morphological differences among these sarcocysts are difficult to distinguish by light microscopy. Thus, molecular analysis is necessary for the identification of S. hominis, which has been implicated as a human pathogen.

\section{Identification of sarcocysts}

When sequencing the $18 \mathrm{~S}$ rRNA gene from $S$. fayeri sarcocysts isolated from horsemeat samples, it was difficult to obtain good sequences from all except a single Italian sample. In general, the $18 \mathrm{~S}$ rRNA gene exhibits low variation, and it has therefore been widely used in the identification of parasites. However, after sequencing eight 18S rRNA sequences obtained from individual bradyzoites released from a single $S$. fayeri sarcocyst, the most divergent sequences among the eight samples exhibited
115 base substitutions, insertions, and deletions (out of $1,169 \mathrm{bp}$ ). The maximum and average genetic distances were 0.094 and 0.059 , respectively. The genetic distances between S. cruzi (KT901167) and S. hominis (KF954731), S. bovini (KT901145), S. bovifelis (KC209742), and S. hirsuta (KT901163) were 0.050, 0.048, 0.045, and 0.058 , respectively. Thus, the variation among bradyzoites from a single $S$. fayeri sarcocyst was higher than that among Sarcocystis spp. sarcocysts infecting cattle. Some Sarcocystis spp. have exhibited a high degree of intraspecific variation in the $18 \mathrm{~S}$ rRNA gene, requiring the cloning of PCR products before sequencing $[1,5,6]$. It has been reported that this is probably due to multiple, slightly different variants of the gene in the genome, which may be caused by multiple copies of the $18 \mathrm{~S}$ rRNA gene or by dissimilarities among gene copies from different merozoites within the sarcocyst [1]. Merozoites enter muscle cells and form metrocytes, which begin sarcocyst formation. The sarcocyst then grows through repeated asexual division of the merozoites [2,4]. However, all eight bradyzoite sequences indicated single chromatogram peaks, making it unlikely that the variation is due to the presence of many divergent $18 \mathrm{~S}$ rRNA copies within the genome of each merozoite. Instead, the high sequence divergence among the DNA sequences from many bradyzoites may reflect differences in the genomes of different bradyzoites. Moreover, the fact that a single sequence was obtained from the Italian horsemeat sample suggests that high sequence variation may not occur in all $S$. fayeri sarcocysts. The mtDNA cox1 sequences from the six cyst fragments of a single sarcocyst were $100 \%$ identical. Compared with these sequences, sequences from the four other sarcocysts isolated from the same Canadian horsemeat sample had 5-8 base substitutions between them. It is unlikely that this is due to the presence of other Sarcocystis spp. or other $S$. fayeri merozoites. Although each $S$. fayeri sarcocyst may develop from a single merozoite, the cause of such variation among 18S rRNA sequences of individual bradyzoites from a single $S$. fayeri sarcocyst is unknown. The phylogenetic analyses of the $18 \mathrm{~S}$ rRNA and mtDNA cox1 genes placed $S$. fayeri within clades that had canids and felids, respectively, as definitive hosts. The topologies of these phylogenetic trees were the same as those observed using different tree-building methods, such as the neighborjoining method (data not shown). It is unknown why S. fayeri clusters with a clade of species with felid hosts, according to the phylogenetic analysis of the mtDNA cox1 gene sequence, as the definitive hosts of $S$. fayer $i$ are canids.

In contrast to sarcocysts isolated from horsemeat samples, S. cruzi and S. hirsuta sarcocysts isolated from beef samples did not exhibit high intraspecific variation in $18 \mathrm{~S}$ rRNA sequences (data not shown). There was, however, intraspecific variation in S. bovini isolates from New Zealand beef samples, and it was necessary to employ cloning to obtain good sequences. In contrast, sequencing of the mtDNA cox 1 gene from $S$. bovini isolates resulted in a good sequence, similar to that of $S$. fayeri. Therefore, sequencing of the mtDNA cox1 gene is more useful for identification of Sarcocystis species. This study also 
provides the first published partial sequence of the S. fayeri mtDNA cox1 gene.

Acknowledgements. We are grateful to Ms. Chikako Kimura, Mr. Shinobu Uchida, and the staff of the Tokyo Metropolitan Institute of Public Health for providing the meat samples. The authors have no conflicts of interest to declare.

\section{References}

1. Dahlgren SS, Gjerde B. 2008. Sarcocystis in moose (Alces alces): molecular identification and phylogeny of six Sarcocystis species in moose, and a morphological description of three new species. Parasitology Research, 103, 93-110.

2. Dubey JP, Calero-Bernal R, Rosenthal BM, Speer CA, Fayer R. 2015. Sarcocystosis of animals and humans, 2nd ed. Boca Raton, Florida: CRC Press.

3. Dubey JP, Streitel RH, Stromberg PC, Toussant MJ. 1977. Sarcocystis fayeri sp. n. from the horse. Journal of Parasitology, 63, 443-447.

4. Fayer R., Esposito DH, Dubey JP. 2015. Human infections with Sarcocystis species. Clinical Microbiology Reviews, 28, 295-311.

5. Gjerde B. 2016. Molecular characterisation of Sarcocystis bovifelis, Sarcocystis bovini n. sp., Sarcocystis hirsuta and Sarcocystis cruzi from cattle (Bos taurus) and Sarcocystis sinensis from water buffaloes (Bubalus bubalis). Parasitology Research, 115, 1473-1492.

6. Gjerde B. 2013. Phylogenetic relationships among Sarcocystis species in cervids, cattle and sheep inferred from the mitochondrial cytochrome c oxidase subunit I gene. International Journal for Parasitology, 43, 579-591.

7. Gjerde B, Hilali M, Mawgood SA. 2015. Molecular characterisation of three regions of the nuclear ribosomal DNA unit and the mitochondrial cox1 gene of Sarcocystis fusiformis from water buffaloes (Bubalus bubalis) in Egypt. Parasitology Research, 114, 3401-3413.

8. Kamata Y, Saito M, Irikura D, Yahata Y, Ohnishi T, Bessho T, Inui T, Watanabe M, Sugita-Konishi Y. 2014. A toxin isolated from Sarcocystis fayeri in raw horsemeat may be responsible for food poisoning. Journal of Food Protection, $77,814-819$.

9. Matsuo K, Sato H. 2012. Prevalence of Sarcocystis in cattle slaughtered in Gifu prefecture. Journal of the Japan Veterinary Medical Association, 65, 791-794 (in Japanese with English summary).

10. Moré G, Schares S, Maksimov A, Conraths FJ, Venturini MC, Schares G. 2013. Development of a multiplex real time PCR to differentiate Sarcocystis spp. affecting cattle. Veterinary Parasitology, 197, 85-94.

11. Ono M, Ohsumi T. 1999. Prevalence of Sarcocystis spp. cysts in Japanese and imported beef (Loin: Musculus longissimus). Parasitology International, 48, 91-94.

12. Pena HF, Ogassawara S, Sinhorini IL. 2001. Occurrence of cattle Sarcocystis species in raw kibbe from Arabian food establishments in the city of São Paulo, Brazil, and experimental transmission to humans. Journal of Parasitology, 87, 1459-1465.

13. Pritt B, Trainer T, Simmons-Arnold L, Evans M, Dunams D, Rosenthal BM. 2008. Detection of Sarcocystis parasites in retail beef: a regional survey combining histological and genetic detection methods. Journal of Food Protection, 71, $2144-2147$.

14. Saito M. 2012. Food poisoning caused by Sarcocystis fayeri associated with ingestion of raw horse meat. Journal of Veterinary Epidemiology, 16, 114-125 (in Japanese with English summary)

15. Saito M, Arai Y, Kamata Y, Konishi Y, Hashimoto K. 2013. Diarrheagenicity of Sarcocystis fayeri in rabbits. Journal of the Japan Veterinary Medical Association, 66, 813-815 (in Japanese with English summary).

16. Tamura K, Stecher G, Peterson D, Filipski A, Kumar S. 2013. MEGA6: Molecular Evolutionary Genetics Analysis version 6.0. Molecular Biology and Evolution, 30, 2725-2729.

17. Thompson JD, Higgins DG, Gibson TJ. 1994. CLUSTAL $\mathrm{W}$ : improving the sensitivity of progressive multiple sequence alignment through sequence weighting, positionspecific gap penalties and weight matrix choice. Nucleic Acids Research, 22, 4673-4680.

18. Yang ZQ, Zuo YX, Yao YG, Chen XW, Yang GC, Zhang YP. 2001. Analysis of the $18 \mathrm{~S}$ rRNA genes of Sarcocystis species suggests that the morphologically similar organisms from cattle and water buffalo should be considered the same species. Molecular and Biochemical Parasitology, 115, 283-288.

Cite this article as: Murata R, Suzuki J, Hyuga A, Shinkai T, Sadamasu K. 2018. Molecular identification and characterization of Sarcocystis spp. in horsemeat and beef marketed in Japan. Parasite 25, 27

\section{PARASTE}

Reviews, articles and short notes may be submitted. Fields include, but are not limited to: general, medical and veterinary parasitology; morphology, including ultrastructure; parasite systematics, including entomology, acarology, helminthology and protistology, and molecular analyses; molecular biology and biochemistry; immunology of parasitic diseases; host-parasite relationships; ecology and life history of parasites; epidemiology; therapeutics; new diagnostic tools.

All papers in Parasite are published in English. Manuscripts should have a broad interest and must not have been published or submitted elsewhere. No limit is imposed on the length of manuscripts.

Parasite (open-access) continues Parasite (print and online editions, 1994-2012) and Annales de Parasitologie Humaine et Comparée (1923-1993) and is the official journal of the Société Française de Parasitologie. 